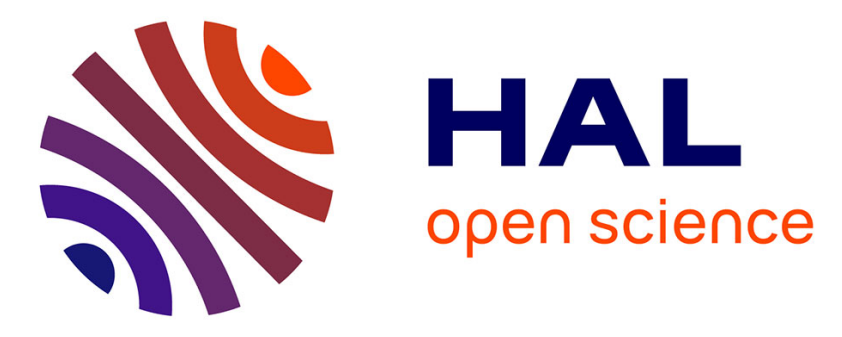

\title{
Triskelion-shaped iridium-helicene NHC complex
}

Etienne S. Gauthier, Nora Hellou, Elsa Caytan, Samuel del Fré, Vincent

Dorcet, Nicolas Vanthuyne, Ludovic Favereau, Monika Srebro-Hooper, J. A.

Gareth Williams, Jeanne Crassous

\section{- To cite this version:}

Etienne S. Gauthier, Nora Hellou, Elsa Caytan, Samuel del Fré, Vincent Dorcet, et al.. Triskelionshaped iridium-helicene NHC complex. Inorganic Chemistry Frontiers, 2021, 8 (16), pp.3916-3925. 10.1039/d1qi00527h . hal-03331038

\section{HAL Id: hal-03331038 https://hal.science/hal-03331038}

Submitted on 21 Sep 2021

HAL is a multi-disciplinary open access archive for the deposit and dissemination of scientific research documents, whether they are published or not. The documents may come from teaching and research institutions in France or abroad, or from public or private research centers.
L'archive ouverte pluridisciplinaire HAL, est destinée au dépôt et à la diffusion de documents scientifiques de niveau recherche, publiés ou non, émanant des établissements d'enseignement et de recherche français ou étrangers, des laboratoires publics ou privés. 


\title{
Triskelion-shaped iridium-helicene NHC complex
}

\author{
Etienne S. Gauthier, ${ }^{a}$ Nora Hellou, ${ }^{a}$ Elsa Caytan, ${ }^{a}$ Samuel Del Fré, ${ }^{b}$ Vincent Dorcet, ${ }^{a}$ Nicolas \\ Vanthuyne, ${ }^{c}$ Ludovic Favereau, ${ }^{a}$ Monika Srebro-Hooper, ${ }^{* b}$ J. A. Gareth Williams, ${ }^{d}$ and Jeanne \\ Crassous*a
}

\begin{abstract}
Enantiopure tris-helicenic chiral-at-iridium complexes have been prepared, constituting the first examples of organometallic metal-tris-helicenes. They have the mer- or $f a c-\operatorname{Ir}\left(\mathrm{C}^{\wedge} \mathrm{C}:\right)_{3}$ form, where $\left(\mathrm{C}^{\wedge} \mathrm{C}:\right)$ is an $\mathrm{N}$-heterocyclic carbene ligand $\mathrm{N}$-substituted with a hexahelicene. Their triskelion geometry and stereochemistry have been thoroughly studied and assigned by NMR in combination with quantum-chemical modelling and by comparison with the $\mathrm{X}$-ray structure of analogues. Thanks to their $\operatorname{Ir}(I I I)$-based multihelicenic architecture, the complexes display strong electronic circular dichroism and optical rotation along with long-lived yellow phosphorescence, involving circularly polarized emission with glum factors around $10^{-3}$
\end{abstract}

\section{A Introduction}

Multihelicenic architectures are currently attracting attention since they are appealing analogues of polycyclic aromatic hydrocarbons (PAHs) and of their heteroatomic versions. ${ }^{1 a, b, d}$ These aesthetic, sophisticated, chiral, extended $\pi$-conjugated molecules have potential applications in optoelectronics as chiral emitters or semi-conducting materials. However, the construction of such polycyclic systems often requires the use of tedious organic chemistry. While purely organic multiple helicenes have recently appeared in the literature, the precise control of their final structure and related chiroptical properties remains highly challenging. ${ }^{1 \mathrm{~d}, 2}$ Conversely, organometallic chemistry enables the development of metal-based helical architectures since a specific metal with an appropriate coordination geometry may give rise to multihelicenic frameworks where the geometry and stereochemistry can be well-controlled. ${ }^{1 c}$ For instance, coordination chemistry around an octahedral $d^{6}$ metal ion such as iridium(III) enables three bidentate $\pi$-conjugated ligands to be organized in a highly stereomerically controlled fashion, accompanied by the generation of photophysical properties that are appealing for many applications. ${ }^{3}$

$\mathrm{N}$-Heterocyclic carbenes (NHCs), with their strong $\sigma$-donor abilities that enable the formation of stable metal-carbon

\footnotetext{
a. Univ Rennes, CNRS, ISCR - UMR 6226, F-35000 Rennes, France. Email: jeanne.crassous@univ-rennes1.fr

b. Faculty of Chemistry, Jagiellonian University, Gronostajowa 2, 30-387 Krakow, Poland.Email: srebro@chemia.uj.edu.p

c. Aix Marseille University, CNRS Centrale Marseille, iSm2, 13284 Marseille, France. d. Department of Chemistry, Durham University, Durham, DH1 3LE, U.K

+ Footnotes relating to the title and/or authors should appear here.

Electronic Supplementary Information (ESI) available: [details of any supplementary information available should be included here]. See
} DOI: $10.1039 / x 0 \times x 00000 x$ bonds, constitute an important family of ligands for organometallic and coordination chemistry. ${ }^{4}$ They have been widely applied in homogeneous catalysis, ${ }^{5}$ and more and more in materials science. 6,7 Recently, chiral organometallic NHC complexes have emerged as a new class of compounds displaying appealing chiroptical properties including circularly polarized luminescence (CPL), $, \mathrm{gg}, 8$ a feature particularly attractive for applications as chiral emitters for organic lightemitting device (OLED) technology, ${ }^{9 a}$ biological imaging, ${ }^{9 b, c}$ or chiral sensing. ${ }^{9 d}$ As both chemical composition and stereochemical environment may strongly influence the photophysics of a system, ${ }^{8}$ it is of great interest to develop novel chiral molecular materials with highly controlled topologies.

In this research article, we report unprecedented trishelicenic architectures, formed of one central $\operatorname{Ir}(\mathrm{III})$ ion surrounded by three hexahelicene-NHC ligands (see 1a, 1b, and $1 \mathrm{c}$ in Figure 1) resulting in unique triskelion (triple-spiral)shaped complexes. These systems give us the opportunity to investigate the stereoselectivity of the coordination process when using a rather crowded chiral NHC ligand. Complexes bearing all combinations of $\mathrm{fac} / \mathrm{mer},(\Delta) /(\Lambda)$ and $(M) /(P)$ configurations can be accessed. They offer scope for a comprehensive study of the photophysical and chiroptical responses of each diastereomerically and enantiomerically pure isomer, i.e. electronic circular dichroism (ECD), optical rotation (OR) and CPL spectra. These triskelion molecules have been examined by a combination of NMR, X-ray structures of model analogues, luminescence, (chir)optical spectroscopy, and quantum-chemical calculations. To our knowledge, these are the first molecules successfully organizing three helicenic ligands around a single metal center. ${ }^{1 c, d}$ 


\section{B Synthetic procedures}

Our synthetic strategy started with the preparation of methylbenzimidazolium salt 6, $\mathrm{N}$-substituted with a carbo[6]helicenic moiety (Scheme 1a). It followed a well-established route to benzimidazoles:10a i) a Hartwig-Buchwald coupling to prepare $\mathrm{N}$-[6]helicenyl-nitroaniline from 2-bromo-carbo[6]helicene (rac)-2 ${ }^{10 \mathrm{~b}}$ and ortho-nitroaniline, ii) a reduction of the nitro group, and iii) cyclization of the obtained $N$-[6]helicen-2-ylortho-phenylene-diamine to benzimidazole. The HartwigBuchwald amination was performed using microwave conditions at $170^{\circ} \mathrm{C}^{10 \mathrm{c}}$ and yielded nitro derivative (rac)-3 as bright red crystals in $64 \%$ yield after column chromatography. This compound was reduced using tin(II) chloride dihydrate under acidic conditions affording helicenic diamino derivative (rac)-4. Owing to its high sensitivity to oxidation, 4 was used directly in the next step without further purification, by heating in triethylorthoformate in the presence of a catalytic amount of $\mathrm{TsOH} \cdot \mathrm{H}_{2} \mathrm{O}$, giving (rac)-5 in $68 \%$ yield after purification by column chromatography. Note that this compound is a more extended analogue of the previously described [4] helicene-2- $N$-benzimidazole. ${ }^{8 b}$

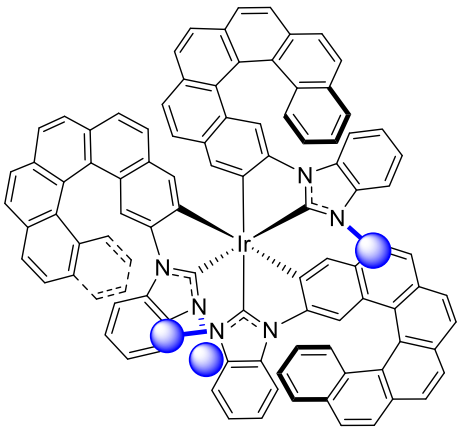

mer-1a

$C_{1}$ symmetry

$\left(M, \Lambda_{\mathrm{lr}}\right) /\left(P, \Delta_{\mathrm{lr}}\right)$

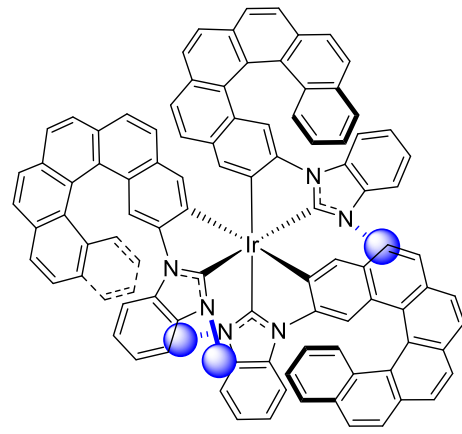

mer-1b

$C_{1}$ symmetry

$\left(M, \Delta_{\mathrm{lr}}\right) /\left(P, \Lambda_{\mathrm{lr}}\right)$

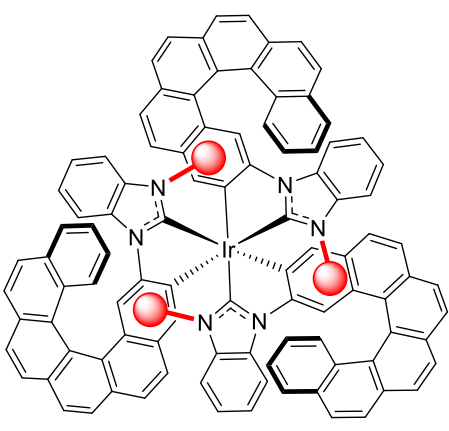

fac-1c

$C_{3}$ symmetry

$\left(M, \Lambda_{\mathrm{lr}}\right) /\left(P, \Delta_{\mathrm{lr}}\right)$

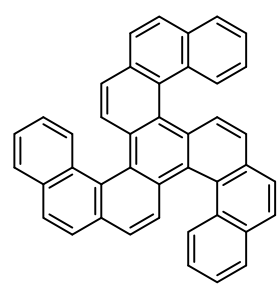

1 '

organic triskel-shaped model

Figure 1. Chemical and stereochemical structure of the prepared chiral mer and fac tris-helicene-NHC-Ir complexes 1a-c. Blue and red bawls denote methyl groups. Fully organic triskel-shaped tris-pentahelicenic model $\mathbf{1}^{\prime} .^{2 f}$

a)

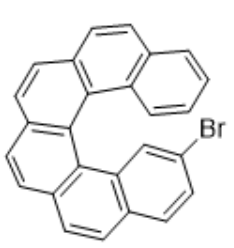

(rac)-2<smiles>Nc1ccccc1[N+](=O)[O-]</smiles>

i)

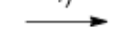

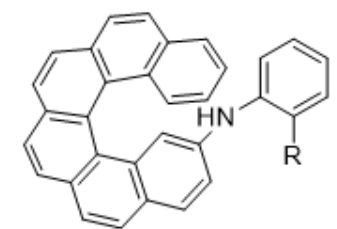

(rac) $-3\left(\mathrm{R}=\mathrm{NO}_{2}\right) \longrightarrow(\mathrm{rac})-\mathbf{4}\left(\mathrm{R}=\mathrm{NH}_{2}\right)$

iii) c)

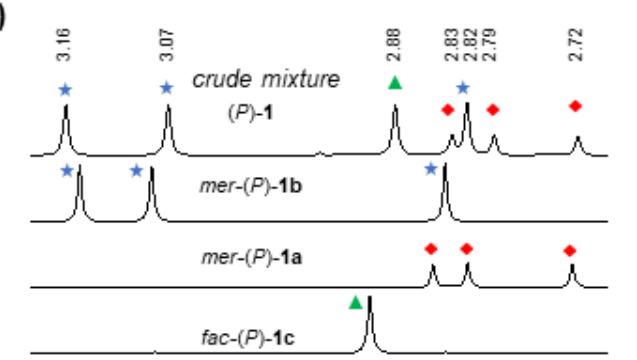

$$
\text { ii) not isolated }
$$

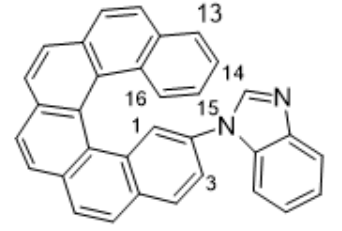

(rac)-5 b)

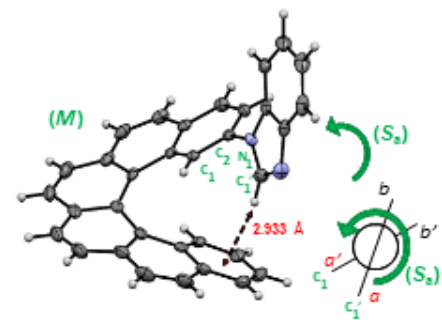

$\left(M, S_{a}\right)-5$

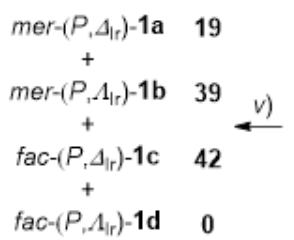

fac- $\left(P, \Lambda_{\mathrm{lr}}\right)-\mathbf{1 d} \quad 0$

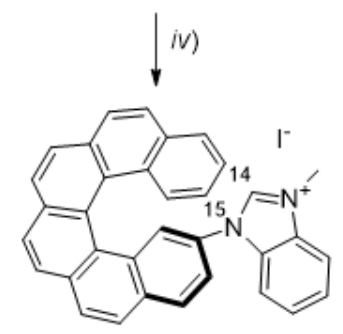

$(P)-(+)-6$

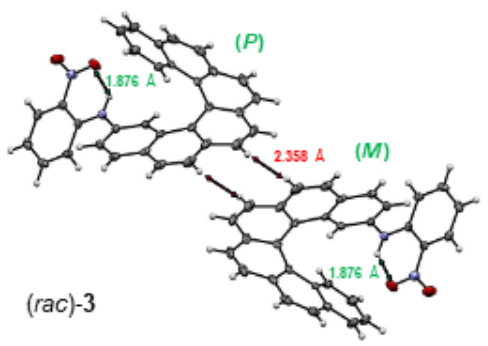

Scheme 1. a) Synthetic route to helicene-imidazolium salts $(P)$ - and $(M)-6$ and to iridium(III)-tris-helicene- $\mathrm{NHC}$ complexes $1 \mathrm{a}-\mathrm{c}$. i) $\mathrm{Pd}(\mathrm{OAc})_{2} / \mathrm{Xantphos}\left(\mathrm{cat}\right.$.), $\mathrm{Cs}_{2} \mathrm{CO}_{3}$, toluene, $\mathrm{MW}, 170^{\circ} \mathrm{C}, 30 \mathrm{~min}, 64 \%$; ii) $\mathrm{SnCl}_{2} \cdot 2 \mathrm{H}_{2} \mathrm{O}, \mathrm{EtOH} / \mathrm{HCl}(2: 1)$, reflux, overnight; iii) $\mathrm{TsOH} \cdot \mathrm{H}_{2} \mathrm{O}$ (cat.), (EtO) ${ }_{3} \mathrm{CH}, 80^{\circ} \mathrm{C}$, overnight, $68 \%$ (over $2 \mathrm{steps}$ ); iv) chiral $\mathrm{HPLC}$ separation, then Mel (excess), $\mathrm{MeCN}$, reflux, overnight; v) $\mathrm{Ag}_{2} \mathrm{O}$, 1,4-dioxane, $60^{\circ} \mathrm{C}$, dark, one night, then $[\operatorname{Ir}(\mathrm{COD}) \mathrm{Cl}]_{2}, 120^{\circ} \mathrm{C}, 24 \mathrm{~h}$. b) X-ray crystallographic structures of (rac)-5 (top, only the $\left(M, S_{a}\right)$ stereoisomer is shown) and $(\mathrm{rac})-\mathbf{3}$ (bottom). $\mathrm{C}^{1}{ }^{1} \mathrm{H}$ NMR of the Me groups of the $(P)$ crude mixture (in $\left.\mathrm{CDCl}_{3}\right)$ and of the corresponding pure stereoisomers of $\mathbf{1 a}$-c obtained (in $\mathrm{CD}_{2} \mathrm{Cl}_{2}$ ).

All these compounds were fully characterized by NMR analysis and HRMS (see SI). Classical signals of protons on the helicenic unit were observed in $\mathrm{CD}_{2} \mathrm{Cl}_{2}$, notably $\mathrm{H}^{15}$ and $\mathrm{H}^{14}$ (pseudo-triplets at 6.84 and 7.38 ppm, respectively) and $\mathrm{H}^{3}$ 
(doublet of doublets at $7.43 \mathrm{ppm}$ ) for ( $\mathrm{rac}$-5. Single crystals of ( $r a c)-3$ and ( $r a c)-5$ suitable for X-ray diffraction were grown by vapor diffusion of $n$-pentane into a solution of the compound in $\mathrm{CH}_{2} \mathrm{Cl}_{2}$. Both compounds crystallized in the centrosymmetric space group $P 2_{1} / \mathrm{n}$ (Scheme $1 \mathrm{~b}$ ). Their helicities (dihedral angle between terminal rings) of $47.80^{\circ}$ and $50.59^{\circ}$, respectively, are typical of hexahelicenes. ${ }^{11}$ Regarding (rac)-3 (see Scheme $1 \mathrm{~b}$ bottom), the nitro and the amino groups are nearly coplanar $\left(\mathrm{N}_{\text {nitro }}-\mathrm{C}-\mathrm{C}-\mathrm{N}_{\text {amine }}\right.$ dihedral angle of $3.16^{\circ}$ ) and establish intramolecular hydrogen bonding interactions $(\mathrm{O}-\mathrm{N}-\mathrm{O} \cdots \mathrm{H}-\mathrm{N})$ that show similar characteristics to those observed for orthonitroanilines $(\mathrm{O} \cdots \mathrm{H}$ distance equal to $1.876 \AA$, $\mathrm{O} \cdots \mathrm{H}-\mathrm{N}$ angle equal to $\left.136.83^{\circ}\right) .{ }^{4}$ The crystal packing is governed by heterochiral interactions, through the aromatic protons located in the central outer part of the helicene (distances of $2.358 \AA$ ) ; furthermore, an arrangement of homochiral columns stabilized via $\mathrm{CH}-\pi$ interactions (distances of $2.770 \AA$ ) appears along the $b$ axis (Figure SI.27). In the case of (rac)-5 (Scheme $1 \mathrm{~b}$ top), interestingly, two stereogenic elements are actually found in the solid state, namely the helicenic unit and the axial chirality around the $\mathrm{N}_{1}-\mathrm{C}_{2}$ bond $\left(\mathrm{C}_{1^{\prime}}-\mathrm{N}_{1}-\mathrm{C}_{2}-\mathrm{C}_{1}\right.$ dihedral angle of $\left.\pm 50.53^{\circ}\right)$ that appears to be associated with an intramolecular $\mathrm{CH} \cdots \pi$ interaction established between the $\mathrm{H}_{\text {imidazole }}$ and the terminal ring of the helicenic core $(2.933 \AA$ A). In the racemic crystal, $(P)$ helices are systematically associated with $\left(R_{\mathrm{a}}\right)$ axial stereochemistry and $(M)$ helices with $\left(S_{\mathrm{a}}\right)$. This confirms that the helical chirality controls the axial chirality through the presence of the intramolecular $\mathrm{CH}_{\text {imidazole }} \cdots \pi$ interaction. Note that such $\mathrm{CH} \cdots \pi$ contacts seem to be also present in solution. Indeed, a strongly shielded signal at $6.77 \mathrm{ppm}$ was observed for the $\mathrm{H}_{\text {imidazole }}$ in $\mathbf{5}$ (which shifted to highly deshielded at 9.31 ppm for methyl-imidazolium 6, vide infra). This observation is corroborated by clear NOESY correlation peaks between this proton and the $\mathrm{H}^{1}$ one in $\mathbf{5}$ (see ESI). Furthermore, although the rotation around the 2-N bond is probably not fully blocked in solution as suggested by rather broad ${ }^{1} \mathrm{H}$ signals observed for the whole benzimidazole unit, low temperature NMR (down to 250K) did not yield any splitted signals. Overall, these observations seem to indicate that the $\left(M, S_{\mathrm{a}}\right) /\left(P, R_{\mathrm{a}}\right)$ stereoisomers might be stable in solution. Finally, as for (rac)3, the supramolecular packing along the $b$ axis in the crystal of (rac)-5 is arranged through homochiral columns (Figure SI.28). Hexahelicenic derivative 5 was accessed in enantiopure $(P)-(+)$ and $(M)-(-)$ forms on $100 \mathrm{mg}$ scale (ee's > 99.5\%) after HPLC separation over a chiral stationary phase (Chiralpak IG). Benzimidazolium salts $(P)-(+)$ - and $(M)-(-)-6$ were then obtained in $>90 \%$ yield by reaction with methyl iodide and used to generate the $\left[\operatorname{Ir}\left(\mathrm{C}^{\wedge} \mathrm{C}:\right)_{3}\right]$ complexes 1 . Following the recently described procedure by Johannes et al., ${ }^{12 a}$ the two enantiopure salts $(M)$ and $(P)-6$ (3 eq.) were engaged in the metalation step by first a reaction with $\mathrm{Ag}_{2} \mathrm{O}$ (1 eq.) upon heating $\left(60^{\circ} \mathrm{C}\right)$ for one night in the dark, followed by addition of $[\operatorname{lr}(\mathrm{COD}) \mathrm{Cl}]_{2}$ (0.5 eq.) and further heating $\left(120^{\circ} \mathrm{C}\right)$ for $24 \mathrm{~h}$. After a filtration over Celite, the ${ }^{1} \mathrm{H}$ NMR of the crude mixture of 1 recorded in $\mathrm{CDCl}_{3}$ showed no deshielded signal around 9-10 ppm confirming the consumption of the benzimidazolium precursor, whilst several new singlets appeared between 2.60 and 3.20 ppm corresponding to the $\mathrm{N}-\mathrm{CH}_{3}$ signals of the desired complexes $\mathbf{1}$, formed as a mixture of diastereoisomers 1a, 1b, and 1c (identical singlets were obtained for both $(P)$ and $(M)$ helicenes, see Scheme 1c, Figures 1, SI.6SI.9, and NMR analysis presented below).

\section{X-ray analysis of triskelion pentahelicenic-NHC-Ir analogues}

All attempts to obtain single crystals of $\mathbf{1 a}, \mathbf{1} \mathbf{b}$ or $\mathbf{1 c}$ failed. However, parallel tests on the synthesis of analogous trishelicenic $\operatorname{Ir}\left(C^{\wedge} C:\right)_{3}$ complexes, prepared using already reported fused pentahelicenic NHC-based $\left(C^{\wedge} \mathrm{C}:\right)$ ligand 7,7 a resulted in a mixture of multiple isomers from which two fac complexes could be successfully crystallized and characterized by X-ray crystallography (see fac- $\left(P, M, M, \Lambda_{\mathrm{lr}}\right)-\mathbf{8 a}$ and fac- $\left(P, M, M, \Delta_{\mathrm{lr}}\right)-\mathbf{8 b}$ in Figure 2). These results provide illustrative insight into the general structural features of the unprecedented triskelionshaped tris-helicene-NHC-Ir complexes 1 . X-ray crystallography of the pure diastereoisomers $8 \mathbf{a}$ and $\mathbf{8 b}\left(P 2_{1} / c\right.$ and $P 2_{1} / n$ centro-symmetric space groups, respectively, $\mathrm{SI}$ ) shows the pseudo-octahedral geometry around the iridium center and the fac relationship of the three tolyl rings, whereas the pentahelicene-NHC chelates are oriented in two ways around the $\operatorname{Ir}(\mathrm{III})$, defining either the delta $\left(\Delta_{\mathrm{Ir}}\right)$ or lambda $\left(\Lambda_{\mathrm{Ir}}\right)$ epimers associated with different helicities, thus yielding fac$\left(P, M, M, \Lambda_{\mathrm{lr}}\right) /\left(M, P, P, \Delta_{\mathrm{lr}}\right)-8 \mathbf{a}$ and fac- $\left(P, M, M, \Delta_{\mathrm{lr}}\right) /\left(M, P, P, \Lambda_{\mathrm{lr}}\right)-\mathbf{8 b}$. The pentahelicene-NHC ligands are bound to one Ir center with classical C-Ir bond-lengths ranging between 2.011 and $2.052 \AA$. Furthermore, the tolyl groups are coordinated to the metal via their C2' atoms (C2'-Ir between 2.049 and $2.106 \AA$ ) and are almost coplanar with the NHC cycles (dihedral angles between 1.67 and $7.24^{\circ}$ ). These metric data correspond well with classical values for tris-carbenic cycloiridiated $\operatorname{Ir}\left(\mathrm{C}^{\wedge} \mathrm{C}:\right)_{3}$ complexes, ${ }^{12}$ and are very similar to the structural parameters of the computed geometries of the systems 1 (vide infra).

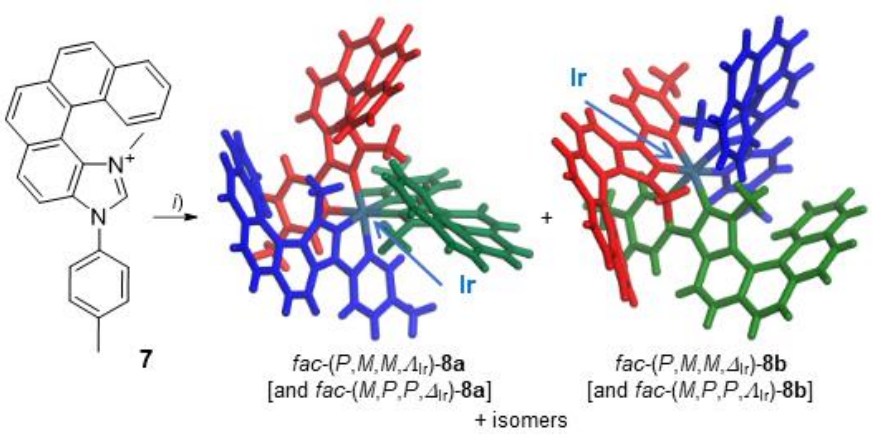

Figure 2. X-ray structures of two fac isomers of iridium(III)-tris-[5]helicene-NHC complexes $\mathbf{8 a}$ and $\mathbf{8 b}$ (only one enantiomer is shown) synthesized using ligand 7. $i$ ) $\mathrm{Ag}_{2} \mathrm{O},[\operatorname{Ir}(\mathrm{COD}) \mathrm{Cl}]_{2}, 1,2$-dichloroethane, $90^{\circ} \mathrm{C}$, dark, $24 \mathrm{~h}$. The red, blue and green colours highlight three different helical branches.

\section{Stereochemical assignment via NMR studies}

The octahedral complex formed through the cyclometalation of three helicenic NHC ligands with an iridium precursor can be statistically obtained in $32\left(2^{5}\right)$ different 
configurations, due to the helical chirality $(P / M)$ of each helicenic ligand (counting for $2^{3}$ possibilities), the chirality-atiridium $\left(\Delta_{\mathrm{lr}} / \Lambda_{\mathrm{lr}}\right)$ and the two coordination geometries ( meridional $=m e r /$ facial $=f a c)$. In the present case, the configuration of the helicene is fixed (either $(P)$ or $(M)$ ), thus reducing the number of statistically possible isomers to pairs of mirror-image compounds:

$\operatorname{mer}-\left(P, \Delta_{\mathrm{lr}}\right) /\left(M, \Lambda_{\mathrm{lr}}\right)=\operatorname{mer}-\left(P, \Delta_{\mathrm{lr}}\right) /\left(M, \Lambda_{\mathrm{lr}}\right) \mathbf{1 a}$;

$\operatorname{mer}-\left(P, \Lambda_{\mathrm{lr}}\right) /\left(M, \Delta_{\mathrm{lr}}\right)=\operatorname{mer}-\left(P, \Lambda_{\mathrm{lr}}\right) /\left(M, \Delta_{\mathrm{lr}}\right) \mathbf{1} \mathbf{b}$;

fac- $\left(P, \Delta_{\mathrm{lr}}\right) /\left(M, \Lambda_{\mathrm{lr}}\right)=$ fac- $\left(P, \Delta_{\mathrm{lr}}\right) /\left(M, \Lambda_{\mathrm{lr}}\right) 1 \mathrm{c}$;

and fac- $\left(P, \Lambda_{\mathrm{lr}}\right) /\left(M, \Delta_{\mathrm{lr}}\right)=$ fac $-\left(P, \Lambda_{\mathrm{rr}}\right) /\left(M, \Delta_{\mathrm{lr}}\right) 1 \mathrm{~d}$

(see Figure 1, Scheme 1c, and discussion below).

From density functional theory (DFT) calculations (TPSS functional coupled with semiempirical dispersion corrections D3, TZVP basis set, continuum solvent model for $\mathrm{CH}_{2} \mathrm{Cl}_{2}$; see $\mathrm{SI}$ for a complete description of the computational protocol applied here), all four isomers were found to be thermodynamically stable and of comparable relative energy values (Table SII.1). However, among these, only 3 pairs of mirror-image isomers were observed in the ${ }^{1} \mathrm{H}$ NMR spectrum depicted in Scheme 1c, and only one fac isomer was found experimentally. Due to the $C_{3}$ symmetry of the fac isomers, the characteristic protons of the $\mathrm{N}-\mathrm{CH}_{3}$ groups should appear as one singlet integrating to 9 protons, while the spectrum of the mer isomers should exhibit 3 different singlets, each integrating to 3 protons, corresponding to the three inequivalent $\mathrm{N}-\mathrm{CH}_{3}$ groups. For each experiment with fixed $(P)$ or $(M)$ configuration of the helicene ligand, the total number of $\mathrm{N}-\mathrm{CH}_{3}{ }^{1} \mathrm{H}$ NMR signals in the crude mixture was equal to 7 , and not 8. From this, it can be concluded that only three, instead of four, different stereoisomers are obtained: mer-1a,b and fac-1c were acquired in respective (19:39:42) and (25:40:35) proportions in the crude $(P)$ and $(M)$ series (vide infra). It is probable that during the reaction performed at high temperature, one fac isomer readily transforms to the slightly more stable one.

Each pure stereoisomer could then be successfully obtained from the crude mixture by HPLC separation; overall, they were obtained with ee's higher than $99 \%$ and in 2 to $18 \%$ yields (see $\mathrm{SI})$. It is noteworthy that for $\operatorname{Ir}\left(\mathrm{C}^{\wedge} \mathrm{C}:\right)_{3}$ complexes hitherto reported, the mer/fac ratio of the cyclometalation is close to $4: 1,12$ while here it was found to be 58:42 and 65:35 for the crude $(P)$ and $(M)$ mixture, respectively. The selectivity for the mer over the fac isomer usually comes from the transient formation of a bridged $\operatorname{dimer}\left[\operatorname{Ir}\left(\mathrm{C}^{\wedge} \mathrm{C}:\right)_{2}(\mu-\mathrm{Cl})\right]_{2}$ with two ligands in mutually trans positions thanks to the trans effect. ${ }^{12 b}$ In our case, the proximity of two sterically crowded $\left(C^{\wedge} \mathrm{C}:\right)$ hexahelicenic units in the trans configuration of the $\mu^{-}$ chloro dimer is however disfavored, and formation of the cis form becomes easier. This helicene-NHC chemistry is thus sufficiently robust to construct three-dimensional architectures with well-defined topologies.

The complete NMR studies $\left({ }^{1} \mathrm{H},{ }^{13} \mathrm{C}, 2 \mathrm{D}\right.$ homonuclear and heteronuclear NMR, performed on $500 \mathrm{MHz}$ or $900 \mathrm{MHz}$ spectrometers) of the optically pure stereoisomers were then conducted in $\mathrm{CD}_{2} \mathrm{Cl}_{2}$, and the analysis of the resulting NMR signals with reference to the calculated geometries of respective molecular configurations enabled their stereochemistries to be definitively assigned. As aforementioned, the $C_{3}$-symmetric $f a c-(M)$-1c complex displays only one set of ${ }^{1} \mathrm{H}$ and ${ }^{13} \mathrm{C}$ NMR signals for the three equivalent helicene- $\mathrm{NHC}$ ligands, with the $\mathrm{N}-\mathrm{CH}_{3}$ methyls protons appearing as a singlet at $2.90 \mathrm{ppm}$ (Scheme 1c) and with the carbenic $C$ atoms giving one signal at $190.6 \mathrm{ppm}$. Conversely, the ${ }^{1} \mathrm{H}$ and ${ }^{13} \mathrm{C}$ NMR spectra of $C_{1}$-symmetric mer stereoisomers are richer. For instance, the ${ }^{1} \mathrm{H}$ NMR spectrum of $\operatorname{mer}-(M)-\mathbf{1 b}$ exhibits three signals at $3.14,3.08$ and 2.83 ppm, readily assigned to the three inequivalent $\mathrm{N}-\mathrm{CH}_{3}$ groups showing in $\mathrm{HMBC}$ clear ${ }^{1} \mathrm{H}-{ }^{13} \mathrm{C}$ heteronuclear correlations with the three deshielded and distinct carbene atoms (see $\mathrm{SI}$ ). Additionally, an unambiguous scalar ${ }^{1} \mathrm{H}-{ }^{13} \mathrm{C}$ coupling with the proton $\mathrm{H}^{4}$ of the ligand $\mathbf{A}$ (around $6.75 \mathrm{ppm}$ ), visible only with the carbene of the ligand $\mathbf{B}$, helped to simultaneously assign $\mathbf{B}$ as the ligand placed trans and $\mathbf{C}$ as the ligand located cis to $\mathbf{A}$ (see Figures $3 \mathrm{e}$ and SI.20). Typical signals of the helicene fragment were also identified for mer- $(M)$-1b, notably $\mathrm{H}^{15}$ which appears as ddd at $7.33 \mathrm{ppm}$ for ligand $\mathbf{A}$, at $6.79 \mathrm{ppm}$ for ligand $\mathbf{B}$, and at $6.67 \mathrm{ppm}$ for ligand $\mathbf{C}$ (see for example Figure 3b).

As the different stereoisomers displayed different NMR spectra, it was of particular interest to know whether - and if yes then how - specific ${ }^{1} \mathrm{H}^{-1} \mathrm{H}$ homonuclear dipolar correlations between the three helicenic ligands might provide information about the stereochemistry at the iridium center. Optimized structures of $\operatorname{mer}-\left(M, \Lambda_{\mathrm{rr}}\right), \operatorname{mer}-\left(M, \Delta_{\mathrm{lr}}\right), \operatorname{fac}-\left(M, \Lambda_{\mathrm{lr}}\right)$, and $\operatorname{fac}-\left(M, \Delta_{\mathrm{rr}}\right)$ were thus analyzed in order to search for configurations with selective short distances and NMR correlations, whilst discarding the other stereochemistries that would not correspond to experimental NMR signals. Satisfyingly, the resolution obtained with the different NMR analyses (at $500 \mathrm{MHz}$ and at $900 \mathrm{MHz}$ ) was sufficient to find discriminative correlations leading to unambiguous assignment of the stereochemistry of each complex $\mathbf{1 a}, \mathbf{1} \mathbf{b}$, and $\mathbf{1 c}$.

As for the $C_{3}$-symmetric fac isomer, dipolar correlations were found between the $\mathrm{N}-\mathrm{CH}_{3}$ group and the $\mathrm{H}^{1}, \mathrm{H}^{14}$ and $\mathrm{H}^{15}$ protons of the helicenic unit (Figure $3 \mathrm{c}$ ). Looking at the optimized fac structures and distances presented in Figure $3 \mathrm{f}$ and Figure SI.23, it seems unlikely that they originate from protons located on the same ligand, as they are far from each other. Accordingly, these correlations have to stem from through-space interactions between protons of two helicenicNHC ligands located in close proximity. In the fac- $\left(M, \Delta_{\mathrm{lr}}\right)$ configuration (Figure SI.23), unlike in $f a c-\left(M, \Lambda_{\mathrm{lr}}\right)$ (Figure 3f), the $\mathrm{N}-\mathrm{CH}_{3}$ group of one ligand appears too far away (> $5 \AA$ ) from $\mathrm{H}^{14}$ and $\mathrm{H}^{15}$ protons of another ligand to lead to any corresponding dipolar correlations. We can thus conclude that fac- $\left(M, \Lambda_{\mathrm{lr}}\right)$ (or its enantiomer, fac- $\left(P, \Delta_{\mathrm{lr}}\right)$ is the configuration of the complex that fits in the NMR analyses in the case of $\mathbf{1 c}$, displaying three clear correlation signals between $\mathrm{N}-\mathrm{CH}_{3}$ of one ligand and $\mathrm{H}^{1}, \mathrm{H}^{14}$ and $\mathrm{H}^{15}$ of the other ligand, while fac$\left(M, \Delta_{\mathrm{lr}}\right) /\left(P, \Lambda_{\mathrm{lr}}\right)-\mathbf{1 d}$ was not found experimentally. 


\section{ARTICLE}

d)

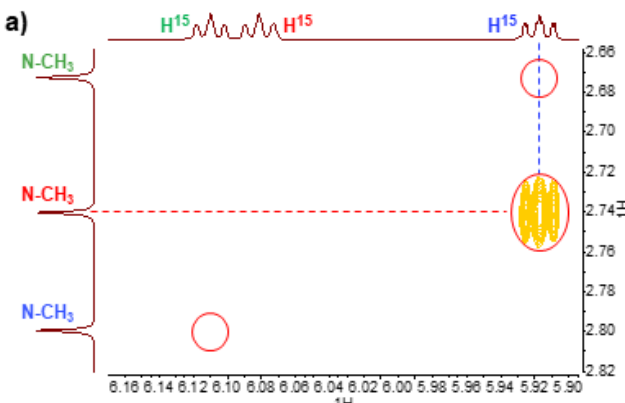

$\operatorname{mer}-\left(M, \Lambda_{\mathrm{l}}\right)-\mathbf{1 a}$

Distance from the $\mathrm{N}-\mathrm{CH}_{3}$ (A) to: $\rightarrow \mathrm{H}^{15}(\mathrm{~B})=3.853 \mathrm{~A}$ Distance from the $\mathrm{N}-\mathrm{CH}_{3}$ (B) to $\rightarrow \mathrm{H}^{15}(\mathrm{C})=7.069 \AA$

Distance from the $\mathrm{N}-\mathrm{CH}_{3}$ (C) to: $\rightarrow \mathrm{H}^{15}(\mathrm{~B})=6.856 \mathrm{~A}$

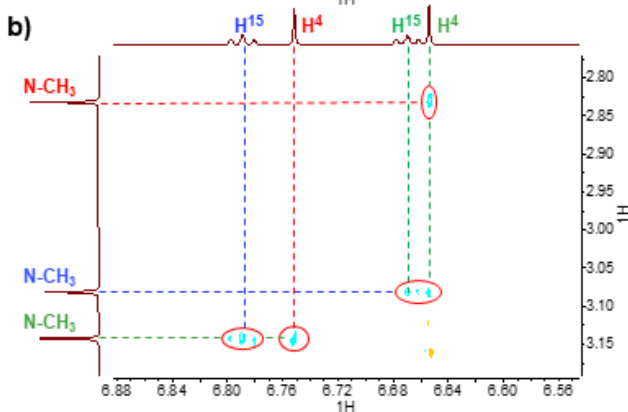

e)

\section{mer- $\left(M, \Delta_{\mid t}\right)-\mathbf{1} \mathbf{b}$}

Distance from the $\mathrm{N}-\mathrm{CH}_{3}$ (A) to: $\rightarrow \mathrm{H}^{4}(\mathrm{C})=3.733 \AA$

Distance from the $\mathrm{N}-\mathrm{CH}_{3}(\mathrm{~B})$ to $\rightarrow \mathrm{H}^{15}(\mathrm{C})=2.996 \mathrm{~A}$

$\rightarrow \mathrm{H}^{4}(\mathrm{C})=3.299 \AA$

Distance from the $\mathrm{N}-\mathrm{CH}_{3}(\mathrm{C})$ to $\rightarrow \mathrm{H}^{15}(\mathrm{~B})=3.253 \mathrm{~A}$

$\rightarrow \mathrm{H}^{4}(\mathrm{~A})=3.702 \AA$

\section{f)}

fac- $\left(M, \Lambda_{\mathrm{lr}}\right)-\mathbf{1 c}$

Distances from the $\mathrm{N}-\mathrm{CH}_{3}$ (A) to: $\rightarrow \mathrm{H}^{1}(\mathrm{~A})=6.625 \AA$ $\rightarrow \mathrm{H}^{14}(\mathrm{~A})=6.901 \AA$

$\rightarrow \mathrm{H}^{1}(\mathrm{~B})=4.562 \AA$

$\rightarrow \mathrm{H}^{14}(\mathrm{~B})=2.609 \AA$

$\rightarrow \mathrm{H}^{15}(\mathrm{~B})=3.561 \AA$
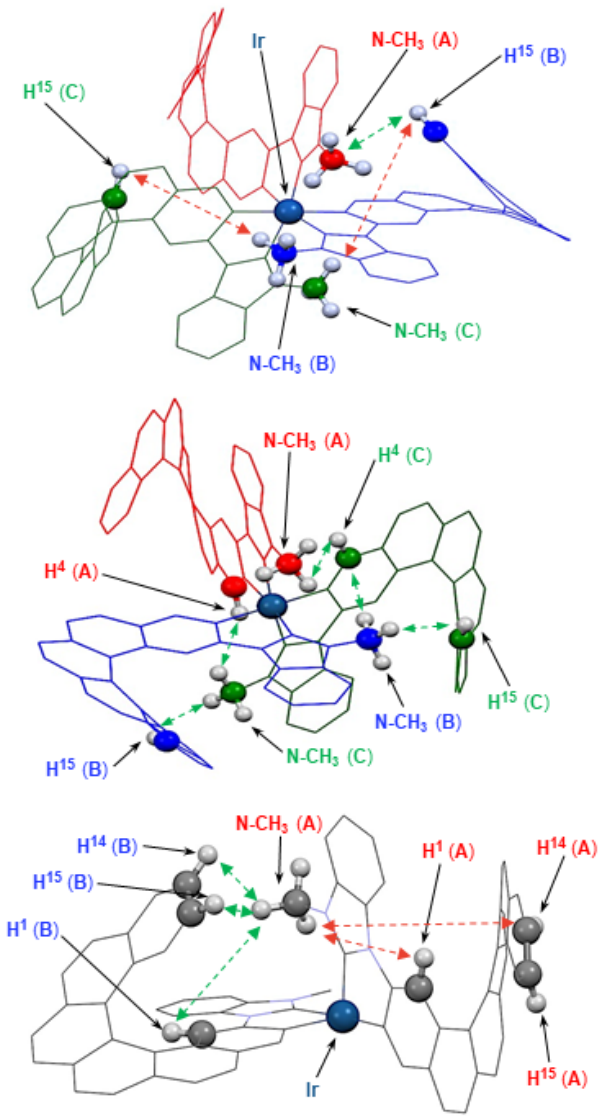

Figure 3. a)-c) ${ }^{1} \mathrm{H}-{ }^{1} \mathrm{H}$ homonuclear correlations observed between the $\mathrm{N}-\mathrm{CH}_{3}$ groups and helicenic protons $\left(\mathrm{CD}_{2} \mathrm{Cl}_{2}, 500\right.$ or $900 \mathrm{MHz}$, see $\mathrm{SI}$ for precise conditions) in 1 a-c. d)-f)

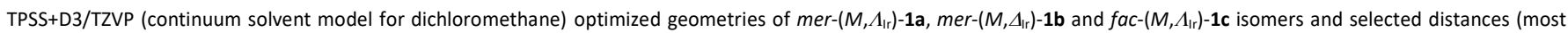
hydrogen atoms and the third ligand of the fac isomer have been omitted for clarity). The three inequivalent hexahelicenic-NHC ligands are denoted A, B and C for clarity. Close distances are highlighted in green, while longer ones are marked in red. See Figure SI. 25 for the corresponding 'capped-sticks' representation of each structure, providing a clearer visualization of the $3 \mathrm{D}$ arrangement of the ligands.

Regarding the NMR data depicted in Figure 3b for one of the two possible mer stereoisomers, the following homonuclear dipolar correlations were noticed: $i$ ) between the $\mathrm{N}-\mathrm{CH}_{3}$ group of ligand $\mathbf{A}$ and $\mathrm{H}^{4}$ of ligand $\mathbf{C}$, ii) between the $\mathrm{N}-\mathrm{CH}_{3}$ group of ligand $\mathbf{B}$ and $\mathrm{H}^{15}$ and $\mathrm{H}^{4}$ of ligand $\mathbf{C}$, and iii) between the $\mathrm{N}-\mathrm{CH}_{3}$ group of ligand $\mathbf{C}$ and $\mathrm{H}^{15}$ of ligand $\mathbf{B}$ and $\mathrm{H}^{4}$ of ligand $\mathbf{A}$. Looking at the computed structure of the $\operatorname{mer}-\left(M, \Delta_{\mathrm{lr}}\right)$ stereoisomer presented in Figure $3 \mathrm{e}$, we can observe that the respective distances between the denoted $\mathrm{N}-\mathrm{CH}_{3}$ group and the $\mathrm{H}^{15}$ of the ligands $\mathbf{B}$ and $\mathbf{C}$, as well as the other protons, are below $3.7 \AA$, which is suitable for spatial correlations. Conversely, considering the mer- $\left(M, \Lambda_{\mathrm{rr}}\right)$ configuration depicted in Figure $3 \mathrm{~d}$, the distances between the $\mathrm{N}-\mathrm{CH}_{3}$ group of ligands $\mathbf{B}$ and $\mathbf{C}$ and $\mathbf{H}^{15}$ of ligands $\mathbf{C}$ and $\mathbf{B}$, respectively, are longer

\section{ACCEPTED MANUSCRIPT}


than $5 \AA$, which is detrimental to observation of dipolar homonuclear correlations in NMR and corresponds well with the correlations depicted in Figure 3a, i.e. only between the $\mathrm{N}$ $\mathrm{CH}_{3}$ group of ligand $\mathbf{A}$ and $\mathrm{H}^{15}$ of ligand $\mathbf{B}$. We can thus unambiguously conclude that the stereochemistry of $\mathbf{1} \mathbf{b}$ is $\operatorname{mer}-\left(M, \Delta_{\mathrm{lr}}\right) /\left(P, \Lambda_{\mathrm{lr}}\right)$, while that of $1 \mathrm{a}$ is $\operatorname{mer}-\left(M, \Lambda_{\mathrm{lr}}\right) /\left(P, \Delta_{\mathrm{lr}}\right)$.

\section{Photophysical properties}

The UV-visible absorption spectra of all the stereoisomers 1a-c were recorded in $\mathrm{CH}_{2} \mathrm{Cl}_{2}$ solution at room temperature and showed close resemblance to one another (see Figure $4 \mathrm{~b}$ ). For mer- $\left(P, \Lambda_{\mathrm{Ir}}\right)-\mathbf{1} \mathbf{b}$, for example, the band of highest intensity was observed at $275 \mathrm{~nm}\left(\varepsilon \sim 90000 \mathrm{M}^{-1} \mathrm{~cm}^{-1}\right)$, followed by a shoulder centered around $308 \mathrm{~nm}$ of nearly half the intensity $\left(\varepsilon \sim 46000 \mathrm{M}^{-1} \mathrm{~cm}^{-1}\right)$ and a band at $357 \mathrm{~nm}\left(\varepsilon \sim 29000 \mathrm{M}^{-}\right.$ $\left.{ }^{1} \mathrm{~cm}^{-1}\right)$. Weaker, lower-energy signals can also be noticed, centered at 404, 428, and $445 \mathrm{~nm}(\varepsilon \sim 10000,4000$, and 950 $\mathrm{M}^{-1} \mathrm{~cm}^{-1}$, respectively).

The general spectral UV-vis envelopes for 1a-c, along with the close similarities between stereoisomers, are overall correctly reproduced by TDDFT calculations (PBEO/SV(P) with a continuum solvent model for $\mathrm{CH}_{2} \mathrm{Cl}_{2}$, see Figure SII.2). The corresponding analysis of molecular orbital (MO) pair contributions to intense excitations confirms the expected $\pi$ $\pi^{*}$ helicene-centered origin of the intense UV-vis signals but also shows pronounced involvements of the metal $d$-orbitals and, in the case of higher-energy excitations, the $\pi$-orbitals of the NHC units, which constitute metal-to-ligand (ML) and intraligand (IL) charge transfers (CTs), respectively. Importantly, the excitations involve electronic transitions both within a single ligand as well as between ligands, and accordingly feature strong ligand-to-ligand (LL) CT character. In particular, the calculations show that the lowest-energy part of the experimental UV-vis spectra of $\mathbf{1 a - c}$ can be attributed to low-energy excitations which correspond predominantly to transitions between high-lying occupied and low-lying unoccupied MOs (see excitations nos. 1-3 in Figure SII.2, computed at 404-393 nm). Electron density in the high-lying occupied MOs is concentrated mainly at the $\operatorname{Ir}($ III) center and adjacent rings of helicene fragments, while the low-lying unoccupied MOs represent purely helicene-centered $\pi$-orbitals either localized at either one of the helicenic NHC ligands (for the $C_{1}$-symmetric mer stereoisomers $\mathbf{1 a}$ and $\mathbf{1 b}$ ) or delocalized over two or all of them (for the $C_{3}$-symmetric fac structure 1c); see HOMO-1, HOMO = highest-occupied MO, LUMO = lowestunoccupied $\mathrm{MO}$, and LUMO+1 presented in Figure $5 \mathrm{~b}$ for $1 \mathrm{a}$ and $1 \mathrm{c}$, and SI for a full set of data. Such character of the frontier MOs in 1 clearly reflects extended $\pi$-conjugation over the whole molecule and efficient electronic interaction between all three helicenic NHC ligands and the metal center. This may also contribute to the stability of these unprecedented tris-helicenic structures. Accordingly, the lowenergy tail in the UV-vis spectra of $\mathbf{1}$ is due to $\pi-\pi^{*}$ transitions within helicene fragments of ILCT-like nature, due to the fact that the engaged MOs are centered in different parts of the helicenic $\pi$-system, accompanied by MLCT and LLCT.

At room temperature in deoxygenated solution, all the complexes 1a-c exhibit structured yellow luminescence, centered at around $540 \mathrm{~nm}$, with modest quantum yields, $\Phi$, between 1 and 3\% (see Table SI.2). The long emission lifetimes under these conditions - between 31 and $81 \mu \mathrm{s}$ - are clearly indicative of phosphorescence from the triplet state, as is typical for many tris-cyclometalated $\operatorname{Ir}(\mathrm{III})$ complexes. This emission is very strongly quenched upon aeration of the sample, in line with the long excited-state lifetimes. For fac$\left(P, \Delta_{\mathrm{lr}}\right)-\mathbf{1 c}$, however, additional weaker emission to high energy of the main band is observed that is insensitive to oxygen. The origin of this emission $<500 \mathrm{~nm}$ thus seems likely to be spinallowed fluorescence from a singlet state. Excitation spectra of fac $-\left(P, \Delta_{\mathrm{lr}}\right)-1 \mathrm{c}$ registered at $\lambda_{\text {exc }}=536$ and $490 \mathrm{~nm}$ (Figure SI.31) both show a reasonable match to the absorption spectra, so it is possible that both emissions originate from the complex. The spin-orbit coupling in the fac- $\left(P, \Delta_{\mathrm{Ir}}\right)-\mathbf{1 c}$ configuration may not be sufficient to render $S_{1} \rightarrow T_{1}$ intersystem crossing so fast as to completely eliminate $\mathrm{S}_{1} \rightarrow \mathrm{S}_{\text {o }}$ fluorescence, as observed for some Pt(II), Ir(III) and Os(II) complexes also bearing large $\pi$ conjugated systems. ${ }^{13}$ The match with the absorption spectra is not perfect, however, and definitive assignment as dual emission cannot be made. We cannot rule out that the fluorescence emanates from a trace of highly emissive impurity, especially as its emission overlaps with that of the complex such that its excitation spectrum cannot be registered independently, and it appears proportionately a little less significant in the enantiomer fac- $\left(M, \Lambda_{\mathrm{rr}}\right)$-1c. The complexes mer- $\left(P, \Delta_{\mathrm{lr}}\right)-\mathbf{1 a}$ or mer- $\left(P, \Lambda_{\mathrm{lr}}\right)-\mathbf{1} \mathbf{b}$, show only phosphorescence in degassed conditions (the trace of weak fluorescence around $450 \mathrm{~nm}$ is almost certainly extraneous and not associated with the complex, based on its high-energy excitation spectrum). The vibronic progression of around $1300 \mathrm{~cm}^{-1}$ in each phosphorescence spectrum is consistent with largely helicenecentered transitions. The rather low quantum yields can then be readily understood, since a low radiative rate constant is anticipated when the triplet state has little metal character, and non-radiative decay will tend to compete effectively.

The geometry of the complex seems to have an impact on the emission since the phosphorescence lifetime of mer$\left(P, \Lambda_{\mathrm{lr}}\right)-\mathbf{1 b}$ is more than twice that of $\operatorname{mer}-\left(P, \Delta_{\mathrm{Ir}}\right)-\mathbf{1 a}(81 \mu \mathrm{s}$ and $31 \mu \mathrm{s}$, respectively). At $77 \mathrm{~K}$, the emission profiles remain similar, with only a slight blue-shift of around $10 \mathrm{~nm}$ relative to room temperature. The suppression of non-radiative pathways under these conditions leads to an increase in the emission lifetimes to around $2 \mathrm{~ms}$ for all of the diastereoisomers (Table SI.2). These very long lifetimes are a further reflection of the primarily $\pi-\pi^{*}$ nature of the transitions and of the limited metal contribution. The fact that the phosphorescence lifetimes became independent of the complex's structure at 77 $\mathrm{K}$ suggests that the difference between the room temperature lifetimes of $\operatorname{mer}-\left(P, \Delta_{\mathrm{Ir}}\right)-\mathbf{1 a}$ and $\operatorname{mer}-\left(P, \Lambda_{\mathrm{Ir}}\right)-\mathbf{1} \mathbf{b}$ arises largely from differing rates of non-radiative decay (Table SI.2). Such a difference might in turn arise from an influence of the complex's geometry on the coupling between electronic and 
vibrational states or on the extent to which the emissive state interacts with the solvent environment.
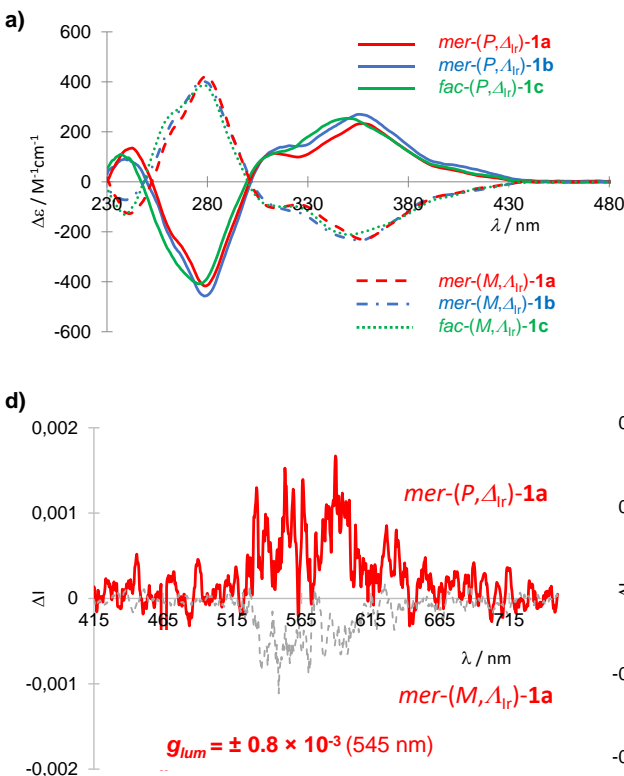

b)
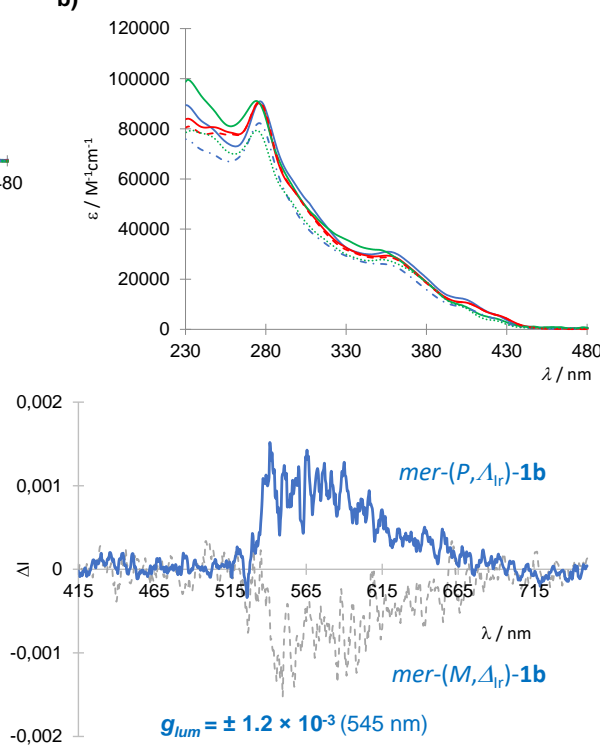

c)

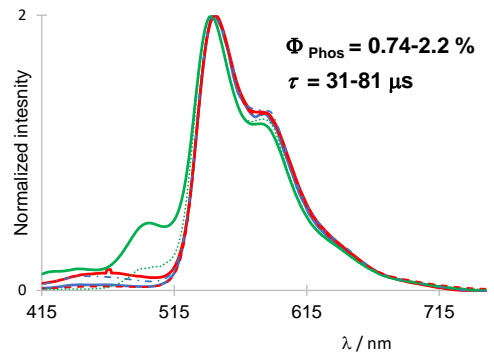

oome

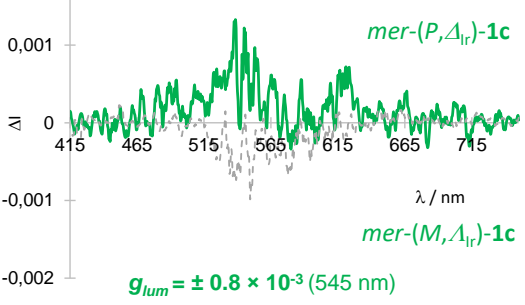

Figure 4. a) Electronic circular dichroism, b) UV-visible absorption, c) luminescence, and d) circularly polarized emission spectra for different stereoisomers of 1a-c measured in $\mathrm{CH}_{2} \mathrm{Cl}_{2}$ at $298 \mathrm{~K}$. See also $\mathrm{SI}$.
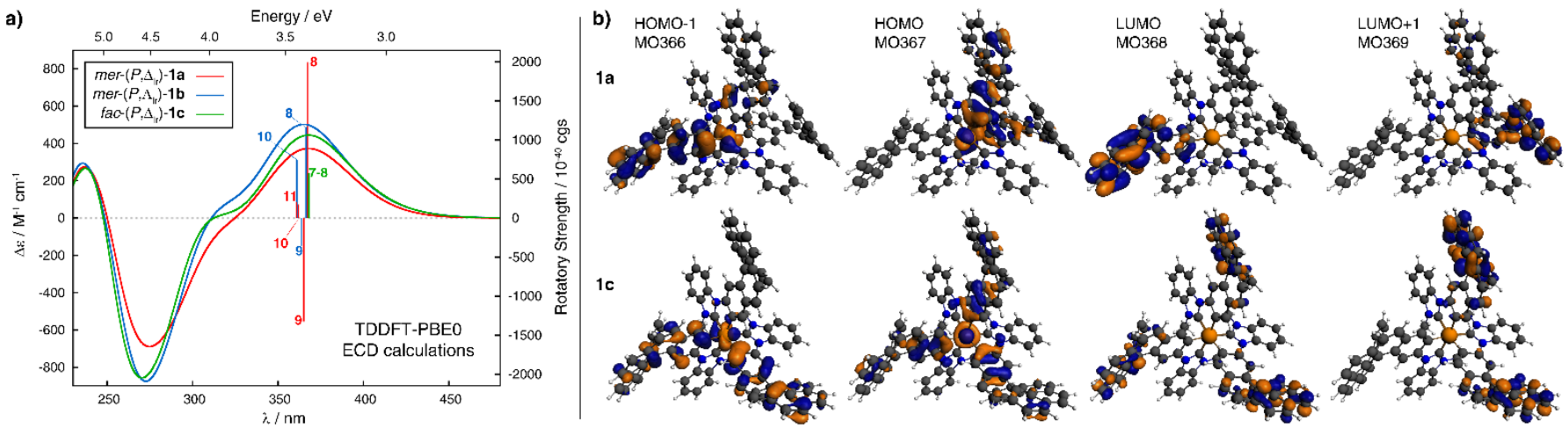

Figure 5. a) Simulated (PBEO/SV(P) with a continuum solvent model for $\mathrm{CH}_{2} \mathrm{Cl}_{2}$ ) ECD spectra of 1a-c with selected excitation energies and rotatory strengths indicated as 'stick' spectra. b) View of frontier MOs for $1 \mathbf{a}$ and $\mathbf{1 c}( \pm 0.03 \mathrm{au})$. See SI for a full set of computed results.

The TDDFT calculations (PBEO/SV(P) with a continuum solvent model for $\mathrm{CH}_{2} \mathrm{Cl}_{2}$, see Table SII.6 and Figure SII.7) of luminescence properties for 1a-c qualitatively support the experimental assignment of dual fluorescence / phosphorescence emission for 1c. They also confirm the overall similar phosphorescence energies and predominantly $\pi-\pi^{*}$ helicene-centered character of the emitting $T_{1}$ excited state, with a clear MLCT contribution for all three stereoisomers. Interestingly, while for $\mathbf{1 c}$ the triplet state appears to be localized on a single ligand, for both mer stereoisomers $\mathbf{1 a}$ and $\mathbf{1} \mathbf{b}$, it shows some delocalization over two or all of the helicene fragments resulting in LLCT signature in their corresponding $\mathrm{T}_{1} \rightarrow \mathrm{S}_{0}$ emission transitions. The role of the helicene moiety in influencing the emission properties of its corresponding metallic system has already been observed in recently reported helicenic NHC metal complexes. ${ }^{8 a, d}$

\section{Chiroptical properties}

The chiroptical properties (OR, ECD, and CPL) of the $\operatorname{Ir}(\mathrm{III})$ complexes 1a-c were also examined. The high values measured for the molar rotations $\left(2.5 \times 10^{4}-3.3 \times 10^{4}\right.$, see SI) are in agreement with data already reported for other multihelicenic organometallic complexes. ${ }^{1 c, d}$ Interestingly, all three tris-helicenic systems presented here demonstrate overall similar OR values in spite of their different 
configurations (chirality-at-iridium and coordination geometry). This might indicate that the contribution of the helical ligand is predominant over the aforementioned configuration-related factors. A synergistic effect of the three helically chiral units linked together is evident, as a 2-fold increase in $[\phi]_{D}^{25}$ is observed relative to monohelicenes. ${ }^{10} \mathrm{~A}$ similar conclusion can be drawn for the ECD spectra. As shown in Figure $4 a$ for the diastereoisomerically pure complexes, the pairs of enantiomers - $\operatorname{mer}-\left(M, \Lambda_{\mathrm{lr}}\right) /\left(P, \Delta_{\mathrm{lr}}\right)-\mathbf{1 a}$, mer$\left(M, \Delta_{\mathrm{r} r}\right) /\left(P, \Lambda_{\mathrm{lr}}\right)-\mathbf{1 b}$, fac- $\left(M, \Lambda_{\mathrm{rr}}\right) /\left(P, \Delta_{\mathrm{r}}\right)-\mathbf{1 c}$ - display expected mirror-image spectra with strong intensities that for a given configuration of the helicene resemble one another. In line with the similar molar rotation values, this confirms the low influence of the chirality-at-metal and coordination geometry on the chiroptical properties of these tris-helicenic complexes. For example, $\operatorname{mer}-\left(P, \Lambda_{\mathrm{lr}}\right)-\mathbf{1 b}$ exhibits a first positive band at 242 $\mathrm{nm}\left(\Delta \varepsilon=+135 \mathrm{M}^{-1} \mathrm{~cm}^{-1}\right)$ followed by a strong negative band at $279 \mathrm{~nm}(\Delta \varepsilon=-417)$. At wavelengths between 300 and $360 \mathrm{~nm}$, the active bands are positive and display slight structure with an increase of intensity from $\Delta \varepsilon=+103 \mathrm{M}^{-1} \mathrm{~cm}^{-1}$ at $310 \mathrm{~nm}$ to $\Delta \varepsilon=+173$ and $+233 \mathrm{M}^{-1} \mathrm{~cm}^{-1}$ at around $342 \mathrm{~nm}$ and $357 \mathrm{~nm}$ respectively. These are then followed by bands of strongly decreased intensity at 402 and $423 \mathrm{~nm}\left(\Delta \varepsilon=+47\right.$ and $+16 \mathrm{M}^{-1}$ $\mathrm{cm}^{-1}$, respectively).

The calculations (TDDFT ${ }^{14}$ with $\mathrm{BHLYP} / \mathrm{SV}(\mathrm{P})$ (for OR) and $\mathrm{PBEO} / \mathrm{SV}(\mathrm{P})$ (for ECD) with a continuum solvent model for $\mathrm{CH}_{2} \mathrm{Cl}_{2}$ ) reproduce correctly the large magnitudes and overall similar chiroptical absorption properties of 1a-c (see Figure 5 a and Table SII.2). In particular, the simulated ECD spectra (see Figures 5a and SII.3) agree reasonably well with experiments enabling us to directly disclose an origin of the strong ECD responses and also to comment on structure-property relationships in these complexes. Analysis of intense excitations computed at around $360 \mathrm{~nm}$ (see excitations nos. 8-11 (1a), 8-10 (1b), and 7-8 (1c) in Figure 5a) for all three complexes was thus performed. It clearly demonstrated predominant $\pi-\pi^{*}$ helicene-centered character of the main positive band in $(P)-\mathbf{1} \mathbf{a}, \mathbf{b}, \mathbf{c}$ with all the underlying excitations corresponding to CT-like $\pi-\pi^{*}$ transitions within helicene moiety localized at either one of the helicenic NHC ligands, mixed with $\mathrm{Ir} \rightarrow$ helicene MLCT and $\pi-\pi^{*}$ helicene $\rightarrow$ helicene transitions engaging different ligands (LLCT). For a complete set of calculated data underlying these assignments, see Tables SII.3-SII.5 and Figures SII.4-SII.6 in SI. Some relevant MOs such as HOMO-1, HOMO and LUMO+1 for $1 \mathrm{a}$ and $1 \mathrm{c}$ are also presented in Figure 5b. Interestingly, in spite of the overall similar electronic character of the dominant excitations computed in this spectral region for all three stereoisomers presented here, the absolute and relative values along with the sign of their corresponding rotatory strength $(R)$ appear to be strongly influenced by the chirality-at-iridium and coordination geometry of the system. For example, for fac$\left(P, \Delta_{\mathrm{Ir}}\right)-\mathbf{1 c}$, intense excitations around $360 \mathrm{~nm}$ demonstrate uniformly positive $R$. On contrast, for the meridional complexes $\mathbf{1 a}$ and $\mathbf{1 b}$, an excitation with sizable, negative $R$ is also present (excitation no. 9 in Figure 5a), and its magnitude is influenced by the chirality at the metal: $\Delta_{\mathrm{lr}} / \Lambda_{\mathrm{lr}}$ leads to a more negative / less negative value respectively. Consequently, in the case of mer- $\left(P, \Delta_{\mathrm{lr}}\right)-1 \mathrm{a}$ the ECD intensity of this negative excitation is not completely suppressed by the intensity of surrounding positive excitations, and a noticeable decrease in the main positive ECD band for this stereoisomer compared to other complexes can be seen in Figure 5a, agreeing well with the experimental trend. All this confirms that the strong chiroptical properties in 1a-c are predominantly a result of synergy in three helical ligands but also clearly indicates that match/mismatch effects of the coordination geometry (fac vs. mer) and chirality-at-metal ( $\Delta_{\mathrm{lr}}$ vs. $\Lambda_{\mathrm{lr}}$ ) are by no means negligible.

Finally, the CPL spectra for all the pairs of pure enantiomeric complexes were recorded. As shown in Figure $4 d$, they exhibit expected mirror-image CPL activity, with the sign of the CPL signals dictated by the configuration of the helicene. Indeed, mer- $(P)-\mathbf{1} \mathbf{a}, \mathbf{b}$ and $f a c-\left(P, \Delta_{\mathrm{lr}}\right)-\mathbf{1 c}$ display positive CPL response with $g_{\text {lum }}$ (at $545 \mathrm{~nm}$ ) of $c a .+0.8 \times 10^{-3}$ for $\operatorname{mer}-\left(P, \Delta_{\mathrm{lr}}\right)-1 \mathrm{a}$ and fac- $\left(P, \Delta_{\mathrm{lr}}\right)-\mathbf{1 c}$ and $+1.2 \times 10^{-3}$ for mer$\left(P, \Lambda_{\mathrm{Ir}}\right)$-1b. Note that precise values are difficult to determine due to the low signal-to-noise ratio in the recorded spectra that results from the rather low quantum yields. Overall the $g_{\text {lum }}$ fall within the classical values for chiral organometallic species.

\section{Conclusions}

In conclusion, we have prepared and characterized the first tris-helicenic metal complexes. These triskelion-type organometallic systems display fac/mer, $\Delta / \Lambda$ and $M / P$ stereochemistries; three epimers were obtained, namely, mer$\left(M, \Lambda_{\mathrm{lr}}\right)-\mathbf{1 a}$, mer- $\left(M, \Delta_{\mathrm{lr}}\right)-\mathbf{1 b}$ and $\operatorname{fac}-\left(M, \Lambda_{\mathrm{lr}}\right)-\mathbf{1 c}$ (and their corresponding mirror-images). Their full stereochemistries were assigned with the help of homonuclear ${ }^{1} \mathrm{H}$ NMR correlations and quantum-chemical modelling. These organometallic triskelions are strong absorbers and reveal ECD spectra with magnitude up to $400 \mathrm{M}^{-1} \mathrm{~cm}^{-1}$. They are also yellow CPL-active phosphors with $g_{\text {lum }}$ values around $10^{-3}$. The study thus enriches the structural diversity of multiple helicenic systems and opens up new perspectives for developments of novel complexes with controlled stereochemistry and topology. Finally, in the course of the synthesis, a transfer of chirality was observed in the solid state (and potentially in solution) in the $N$-[6]helicene-imidazole derivative, displaying stable helical and axial chirality ${ }^{16}$ that will be interesting to exploit in future work.

\section{Author Contributions}

E.S.G and N.H performed the synthesis and samples characterizations. LF performed CPL measurements. EC performed and analyzed NMR measurements. VD performed X-ray analyses. N.V. performed HPLC separations. SDF and M.S.-H. performed theoretical calculations. J.A.G.W. performed and analysed emission 
measurements. J.C. conceived the project, analysed the results and wrote the manuscript with M.S.-H.

\section{Conflicts of interest}

"There are no conflicts to declare".

\section{Acknowledgements}

We thank the Centre National de la Recherche Scientifique (CNRS) and the University of Rennes. This work was supported by the Agence Nationale de la Recherche (ANR-16-CE07-0019 "Hel-NHC" grant). M.S.-H. thanks the PL-Grid Infrastructure and the ACC Cyfronet AGH in Krakow, Poland for providing computational resources. The S2wave platform (Univ. Rennes, Building 10A) is acknowledged for the technical support provided during microwave-assisted syntheses. Some of the NMR experiments were performed on the PRISM core Facility (Biogenouest, UMS Biosit, Université de Rennes 1). Technical and financial support from the IR-RMN-THC FR3050 CNRS for conducting $900 \mathrm{MHz}$ NMR experiments is gratefully acknowledged.

\section{Notes and references}

1 a) C. Li, Y. Yang, Q. Miao, Recent progress in chemistry of multiple helicenes. Chem. Asian J., 2018, 13, 884-894; b) K. Kato, Y. Segawa, K. Itami, Symmetric multiple carbohelicenes. Synlett, 2019, 30, 370-377; c) E. S. Gauthier, R. Rodríguez, J. Crassous, Metal-based multihelicenic architectures. Angew. Chem. Int. Ed., 2020, 59, 22840-22856 d) T. Mori, Chiroptical properties of symmetric double, triple, and multiple helicenes. Chem. Rev., 2021, 121, 2373-2412.

2 Selected examples: a) M. Ball, Y. Zhong, Y. Wu, C. Schenck, F. $\mathrm{Ng}, \mathrm{M}$. Steigerwald, S. Xiao, C. Nuckolls, Contorted Polycyclic Aromatics. Acc. Chem. Res., 2015, 48, 267-276; b) Y. Chen, T. Marszalek, T. Fritz, M. Baumgarten, M. Wagner, W. Pisula, L. Chen, K. Müllen, Contorted polycyclic aromatic hydrocarbons with cove regions and zig-zag edges. Chem. Commun., 2017, 53, 8474-8477; c) T. Hosokawa, Y. Takahashi, T. Matsushima, S. Watanabe, S. Kikkawa, I. Azumaya, A. Tsurusaki, K. Kamikawa, Synthesis, structures, and properties of hexapole helicenes: assembling six [5] helicene substructures into highly twisted aromatic systems. J. Am. Chem. Soc., 2017, 139, 18512-18521; d) M. Roy, V. Berezhnaia, M. Villa, N. Vanthuyne, M. Giorgi, J.-V. Naubron, S. Poyer, V. Monnier, L. Charles, Y. Carissan, D. Hagebaum-Reignier, J. Rodriguez, M. Gingras, Y. Coquerel, Stereoselective syntheses, structures, and properties of extremely distorted chiral nanographenes embedding hextuple helicenes. Angew. Chem. Int. Ed., 2020, 59, 3264-3271; e) K. Kato, Y. Segawa, L. T. Scott, K. Itami, A quintuple [6] helicene with a corannulene core as a $C_{5^{-}}$ symmetric propeller-shaped $\pi$-system. Angew. Chem. Int. Ed., 2018, 57, 1337-1341; f) H. Tanaka, Y. Kato, M. Fujiki, Y. Inoue, T. Mori, Combined experimental and theoretical study on circular dichroism and circularly polarized luminescence of configurationally robust D3-symmetric triple pentahelicene. J. Phys. Chem. A, 2018, 122, 7378-7384; g) C. M. Cruz, I. R. Márquez, S. Castro-Fernández, J. M. Cuerva, E. Maçôas, A. G. Campaña, A triskelion-shaped saddle-helix hybrid nanographene. Angew. Chem. Int. Ed., 2019, 58, 8068-8072.

3 a) S. Sprouse, K. A. King, P. J. Spellane, R. J. Watts, Photophysical effects of metal-carbon.sigma.bonds in orthometalated complexes of iridium(III) and rhodium(III). J. Am. Chem. Soc., 1984, 106, 6647-6653; b) K. A. King, P. J. Spellane, R. J. Watts, Excited-state properties of a triply ortho-metalated iridium(III) complex. J. Am. Chem. Soc., 1985, 107, 1431-1432; c) V. Balzani, A. Credi, F. Scandola, In Transition Metals in Supramolecular Chemistry, L. Fabbrizzi, A. Poggi (Eds.), Kluwer: Dordrecht, The Netherlands, 1994; d) V. Balzani, A. Juris, M. Venturi, S. Campagna, S. Serroni, Luminescent and redox-active polynuclear transition metal complexes. Chem. Rev., 1996, 96, 759-833; e) A. von Zelewsky, Stereochemistry of Coordination Compounds, J. \& Wiley \& Sons, Chichester, 1996; f) A. Amouri, M. Gruselle, Chirality in Transition Metal Chemistry: Molecules, Supramolecular Assemblies and Materials, Wiley-VCH, 2009.

4 a) D. Bourissou, O. Guerret, F. P. Gabbai, G. Bertrand, Stable carbenes. Chem. Rev., 2000, 100, 39-91; b) S. Díez-González (Ed.), N-Heterocyclic Carbenes: From Laboratory Curiosities to Efficient Synthetic Tools, RSC: Cambridge, UK; 2011; c) M. N. Hopkinson, C. Richter, M. Schedler, F. Glorius, An overview of N-heterocyclic carbenes. Nature, 2014, 510, 485496.

5 a) S. Diez-Gonzalez, N. Marion, S. P. Nolan, N-heterocyclic carbenes in late transition metal catalysis. Chem. Rev., 2009, 109, 3612-3676; b) V. César, S. Bellemin-Laponnaz, L. H. Gade, Chiral N-heterocyclic carbenes as stereodirecting ligands in asymmetric catalysis. Chem. Soc. Rev., 2004, 33, 619-636; c) F. Wang, L.-J. Liu, W. Wang, S. Li, M. Shi, Chiral NHC-metal-based asymmetric catalysis. Coord. Chem. Rev., 2012, 256, 804-853; d) D. Zhao, L. Candish, D. Paul, F. Glorius, N-heterocyclic carbenes in asymmetric hydrogenation. ACS Catal., 2016, 6, 5978-5988.

6 a) M. Mercs, M. Albrecht, Beyond catalysis: N-heterocyclic carbene complexes as components for medicinal, luminescent, and functional materials applications. Chem. Soc. Rev., 2010, 39, 1903-1912; b) R. Visbal, M. C. Gimeno, Nheterocyclic carbene metal complexes: photoluminescence and applications. Chem. Soc. Rev., 2014, 43, 3551-3574; c) C. A. Smith, M. R. Narouz, P. A. Lummis, I. Singh, A. Nazemi, C.$\mathrm{H}$. Li, C. M. Crudden, N-heterocyclic carbenes in materials chemistry. Chem. Rev., 2019, 119, 4986-5056.

7 Selected: a) Y. Unger, D. Meyer, T. Strassner, Blue phosphorescent platinum(ii) tetracarbene complexes with bis(triazoline-5-ylidene) ligands. Dalton Trans., 2010, 39, 4295-4301; b) T. Sajoto, P. I. Djurovich, A. Tamayo, M. Yousufuddin, R. Bau, M. E. Thompson, R. J. Holmes, R. S. Forrest, Blue and near-UV phosphorescence from iridium complexes with cyclometalated pyrazolyl or n-heterocyclic carbene ligands. Inorg. Chem., 2005, 44, 7992-8003; c) S. U. Son, K. H. Park, Y.-S. Lee, B. Y. Kim, C. H. Choi, M. S. Lah, Y. H. Jang, D.-J. Jang, Y. K. Chung, Synthesis of Ru(II) complexes of $\mathrm{N}$-heterocyclic carbenes and their promising photoluminescence properties in water. Inorg. Chem., 2004, 43, 6896-6898; d) D. Di, A. S. Romanov, L.Yang, J. M. Richter, J. P. H. Rivett, S. Jones, T. H. Thomas, M. A. Jalebi, R. H. Friend, M. Linnolahti, M. Bochmann, D. Credgington, Highperformance light-emitting diodes based on carbene-metalamides. Science, 2017, 356, 159-163; e) R. Hamze, S. Shi, S. C. Kapper, D. S. M. Ravinson, L. Estergreen, M.-C. Jung, A. C. Tadle, R. Haiges, P. I. Djurovich, J. L. Peltier, R. Jazzar, G. Bertrand, S. E. Bradforth, M. E. Thompson, "Quick-silver" from a systematic study of highly luminescent, twocoordinate, $\mathrm{d}^{10}$ coinage metal complexes. J. Am. Chem. Soc., 2019, 141, 8616-8626; f) R. Hamze, J. L. Peltier, D. Sylvinson, M. Jung, J. Cardenas, R. Haiges, M. Soleilhavoup, 
R. Jazzar, P. I. Djurovich, G. Bertrand, M. E. Thompson, Eliminating nonradiative decay in $\mathrm{Cu}(\mathrm{I})$ emitters: $>99 \%$ quantum efficiency and microsecond lifetime. Science, 2019, 363, 601-606; g) M. Deng, N. F. M. Mukthar, N. D. Schley, G. Ung, Yellow circularly polarized luminescence from $\mathrm{C}_{1^{-}}$ symmetrical copper(I) complexes. Angew. Chem. Int. Ed., 2020, 59, 1228-1231; h) H. Tatsuno, et al. Hot branching dynamics in a light-harvesting iron carbene complex revealed by ultrafast $\mathrm{X}$-ray emission spectroscopy. Angew. Chem. Int Ed., 2020, 59, 364-372; i) C. -F. Chang, Y. -M. Cheng, Y. Chi, Y. -C. Chiu, C. -C. Lin, G. -H. Lee, P. -T. Chou, C. -C. Chen, C. -H Chang, C. -C. Wu, Highly efficient blue-emitting iridium(III) carbene complexes and phosphorescent OLEDs. Angew. Chem. Int. Ed., 2008, 47, 4542-4545; j) P. -H. Lanoë, J. Chan, G. Gontard, F. Monti, N. Armaroli, A. Barbieri, H. Amouri, Deep-red phosphorescent iridium(III) complexes with chromophoric $\mathrm{N}$-heterocyclic carbene ligands: design, photophysical properties, and DFT calculations. Eur. J. Inorg. Chem., 2016, 1631-1634.

8 a) N. Hellou, M. Srebro-Hooper, L. Favereau, F. Zinna, E. Caytan, L. Toupet, V. Dorcet, M. Jean, N. Vanthuyne, J. A. G. Williams, L. Di Bari, J. Autschbach, J. Crassous, Enantiopure cycloiridiated complexes bearing a pentahelicenic $\mathrm{N}$ heterocyclic carbene and displaying long-lived circularlypolarized phosphorescence. Angew. Chem. Int. Ed., 2017, 56 8236-8239; b) A. Macé, N. Hellou, J. Hammoud, C. Martin, E. S. Gauthier, L. Favereau, T. Roisnel, E. Caytan, G. Nasser, N. Vanthuyne, J. A. G. Williams, F. Berrée, B. Carboni, J. Crassous, An enantiopure cyclometallated iridium complex displaying long-lived phosphorescence both in solution and in the solid state. Helv. Chim. Acta, 2019, 102, e1900044; c) N. Hafedh, L. Favereau, E. Caytan, T. Roisnel, M. Jean, N Vanthuyne, F. Aloui, J. Crassous, Synthesis and chiroptical properties of organometallic complexes of helicenic $\mathrm{N}$ heterocyclic carbenes. Chirality, 2019, 31, 1005-1013; d) E. S. Gauthier, L. Abella, N. Hellou, B. Darquié, E. Caytan, T. Roisnel, N. Vanthuyne, L. Favereau, M. Srebro-Hooper, J. A. G. Williams, J. Autschbach, J. Crassous, Long-lived circularlypolarized phosphorescence in helicene-NHC-rhenium(I) complexes: the influence of helicene, halogen and stereochemistry on emission properties. Angew. Chem. Int. Ed., 2020, 59, 8394-8400.

9 a) D.-W. Zhang, M. Li, C.-F. Chen, Recent advances in circularly polarized electroluminescence based on organic light-emitting diodes. Chem. Soc. Rev., 2020, 49, 1331-1343; b) J. Zhang, L. Dai, A. M. Webster, W. T. K. Chan, L. E. Mackenzie, R. Pal, S. L. Cobb, G.-L. Law, Unusual magnetic field responsive circularly polarized luminescence probes with highly emissive chiral europium(III) complexes. Angew. Chem. Int. Ed., 2021, 60, 1004-1010; c) K. Staszak, K. Wieszczycka, V. Marturano, B. Tylkowski, Lanthanides complexes - Chiral sensing of biomolecules. Coord. Chem. Rev., 2019, 397, 76-90; d) Q. Jin, F. Wang, S. Chen, L. Zhou, H. Jiang, L. Zhang, M. Liu, Circularly polarized luminescence of aluminum complexes for chiral sensing of amino acid and amino alcohol. Chem. Asian J., 2020, 15, 319-324.

10 a) P. Ruiz-Castillo, S. L. Buchwald, Applications of palladiumcatalyzed C-N cross-coupling reactions. Chem. Rev., 2016 116, 12564-12649; b) D. A. Lightner, D. T. Hefelfinger, T. W. Powers, G. W. Frank, K. N. Trueblood, Hexahelicene. Absolute configuration. J. Am. Chem. Soc., 1972, 94, 34923497; c) M. Jakubec, T. Beránek, P. Jakubík, J. Sýkora, J. Žádný, V. Církva, J. Storch, -Bromo[6]helicene as a key intermediate for [6] helicene functionalization. J. Org. Chem., 2018, 83, 3607-3616.

11 a) C.-F. Chen, Y. Shen, Helicene Chemistry: From Synthesis to Applications, Springer Berlin Heidelberg: Berlin, Heidelberg, 2017; b) K. Dhbaibi, L. Favereau, J. Crassous, Enantioenriched helicenes and helicenoids containing main-group elements (B, SI, N, P). Chem. Rev., 2019, 119, 8846-8953.

12 a) J. G. Osiak, T. Setzer, P. G. Jones, C. Lennartz, A. Dreuw, W Kowalsky, H.-H. Johannes, Twist it! The acid-dependent isomerization of homoleptic carbenic iridium(III) complexes. Chem. Commun., 2017, 53, 3295-3298; b) C.-H. Chien, S. Fujita, S. Yamoto, T. Hara, T. Yamagata, M. Watanabe, K. Mashima, Stepwise and one-pot syntheses of $\operatorname{Ir}(I I I)$ complexes with imidazolium-based carbene ligands. Dalton Trans., 2008, 916-923; c) J. Lee, H.-F. Chen, T. Batagoda, C. Coburn, P. I. Djurovich, M. E. Thompson, S. R. Forrest, Deep blue phosphorescent organic light-emitting diodes with very high brightness and efficiency. Nature Mater., 2016, 15, 9298; d) B. J. Coe, S. J. Glenwright, Trans-effects in octahedral transition metal complexes. Coord. Chem. Rev., 2000, 203, 580; e) S. L. Dabb, N. C. Fletcher, Mer and fac isomerism in tris chelate diimine metal complexes. Dalton Trans., 2015, 44, 4406-4422.

13 a) D. N. Kozhevnikov, V. N. Kozhevnikov, M. Z. Shafikov, A. M. Prokhorov, D. W. Bruce, J. A. G. Williams, Phosphorescence vs fluorescence in cyclometalated platinum(II) and iridium(III) complexes of (oligo)thienylpyridines. Inorg. Chem., 2011, 50, 3804-3815; b) P.-T. Chou, Y. Chi, M.-W. Chung, C.-C. Lin, Harvesting luminescence via harnessing the photophysical properties of transition metal complexes. Coord. Chem. Rev., 2011, 255, 2653-2665; c) Y.-L. Chen, S.-W. Li, Y. Chi, Y.-M. Cheng, S.-C. $\mathrm{Pu}, \mathrm{Y} . \mathrm{-S}$. Yeh, P.-T. Chou, Switching luminescent properties in osmium-based $\beta$-diketonate complexes. ChemPhysChem, 2005, 6, 2012-2017.

14 a) M. Srebro-Hooper, J. Autschbach, Calculating natural optical activity of molecules from first principles. Annu. Rev. Phys. Chem., 2017, 68, 399-420; b) J. Autschbach, Computing chiroptical properties with first-principles theoretical methods: Background and illustrative examples. Chirality, 2009, 21, E116-E152.

15 a) B. Doisteau, J. -R. Jiménez, C. Piguet, Beyond chiral organic (p-block) chromophores for circularly polarized luminescence: the success of $d$-block and f-block chiral complexes. Front. Chem., 2020, 8, 555 ; b) L. Arrico, L. Di Bari, F. Zinna, Quantifying the overall efficiency of circularly polarized emitters. Chem. Eur. J., 2021, 27, 2920-2934.

16 A. Macé, K. Hamrouni, E. S. Gauthier, M. Jean, N. Vanthuyne, L. Frédéric, G. Pieters, E. Caytan, T. Roisnel, F. Aloui, M. Srebro-Hooper, B. Carboni, F. Berrée, J. Crassous, Chem. Eur. J., 2021, 27, 7959-7967. 